\title{
PERBANDINGAN MOTIVASI DAN PRESTASI BELAJAR MENGGUNAKAN METODE DEMONSTRASI DAN METODE EXAMPLE NON EXAMPLE PADA MATA PELAJARAN MENGGAMBAR INTERIOR DAN EKSTERIOR BANGUNAN KELAS XI TEKNIK GAMBAR BANGUNAN (TGB) SMK NEGERI 2 SUKOHARJO Rizal Nurudin ${ }^{1}$, Anis Rahmawati ${ }^{2}$, Sutrisno ${ }^{3}$
}

\begin{abstract}
ABSTRAK
Tujuan penelitian ini adalah, (1) Mengetahui perbandingan motivasi belajar menggunakan metode demonstrasi dan metode example non example pada mata pelajaran menggambar interior dan eksterior bangunan di kelas XI TGB SMK N 2 Sukoharjo. (2) Mengetahui perbandingan prestasi belajar siswa menggunakan metode demonstrasi dan metode example non example pada mata pelajaran menggambar interior dan eksterior bangunan di kelas XI TGB SMK N 2 Sukoharjo.

Penelitian ini menggunakan metode eksperimen dengan desain penelitian Intact-Group Comparison. Populasi dalam penelitian ini adalah siswa kelas XI TGB dengan jumlah 66. Sampel penelitian diambil sebanyak 32 siswa yang terbagi dalam dua kelas yaitu satu kelas dengan metode demonstrasi dan satu kelas dengan metode example non example dengan jumlah masing-masing kelas sebanyak 16 siswa. Teknik pengumpulan data yang digunakan dalam penelitian ini menggunakan dokumentasi, angket dan observasi. Validitas intrumen penelitian dengan menggunakan uji validitas dan reliabilitas. Teknik analisis data menggunakan uji beda (t-test).

Hasil penelitian menunjukan bahwa (1) Nilai rata-rata motivasi belajar dengan metode demonstrasi lebih besar dibanding metode example non example sebesar 57,30 $>$ 53,70. Dari hasil uji t diperoleh nilai $\mathrm{t}$ hitung $=4,14>\mathrm{t}$ tabel $=$ 2,101 (2) Nilai rata-rata prestasi belajar metode demonstrasi lebih besar dibanding metode example non example sebesar 86,25 > 81,75. Dari hasil uji t diperoleh nilai $\mathrm{t}$ hitung $=7,89>\mathrm{t}$ tabel $=2,145$. Berdasarkan hasil analisis data penelitian dapat disimpulkan bahwa metode demonstrasi dapat meningkatkan motivasi dan prestasi belajar dibandingkan dengan metode example non example pada mata pelajaran menggambar interior dan eksterior di kelas XI TGB SMK N 2 Sukoharjo.
\end{abstract}

Kata Kunci : Metode Demonstrasi, Metode Example non Example, Motivasi Belajar, Prestasi Belajar

1. Pendidikan Teknik Bangunan Universitas Sebelas Maret

2. Dosen Pembimbing: 1. Anis Rahmawati, S.T., M.T.

2. Drs. Sutrisno M.Pd 


\begin{abstract}
THE COMPARISON OF LEARNING MOTIVATION AND
ACHIEVEMENT USES DEMONSTRATION METHOD AND EXAMPLE NON EXAMPLE METHOD IN INTERIOR AND EXTERIOR BUILDING DRAWING SUBJECT IN CLASS XI TGB SMK NEGERI 2 SUKOHARJO Rizal Nurudin ${ }^{1}$, Anis Rahmawati ${ }^{2}$, Sutrisno ${ }^{3}$
\end{abstract}

\begin{abstract}
This purpose of this research was, (1) Find out the comparison of student's motivation used demonstration method and example non example method in interior and exterior building drawing subject in class XI TGB SMK N 2 Sukoharjo. (2) Find out the comparison of student's learning achievement used demonstration method and example non example method in interior and exterior building drawing subject in class XI TGB SMK N 2 Sukoharjo.

This research used experimental method with Intact-Group Comparison research design. Population of this research was students of class XI TGB which total was 66 students. This research took 32 students as the sample that was divided into two class which was one class with demonstration method and another with example non example method, each group consist of 16 students. The data of this research were collected by using documentation, questionnaire and observation. To keep the instrument valid, this research uses validity and reliability test. To analyze the data, the researcher uses t-test computation.

The result of the research showed that (1) Mean score of students' learning motivation with demonstration method was higher than example non example method. It was 57,30 >53,70. From the result of t-test obtained that t score computation $=4,14>\mathrm{t}$ table $=2,101$. (2) Mean score of students' learning achievement with demonstration method was higher than example non example method. It was $86,25>81,75$. From the result of t-test obtained that $t$ score computation $=7,89>\mathrm{t}$ table $=2,145$. Based on the result of the data analysis, it can be concluded that demonstration method can be improve motivation and learning achievement compared with example non example method in interior and exterior building drawing subject in class XI TGB SMK N 2 Sukoharjo.
\end{abstract}

Keyword : Demonstration Method, Example non Example Method, Learning motivation, Learning achievement

1. Vocational Technical Education, Sebelas Maret University

2. Thesis Consultant: $1^{\text {st }}$ Anis Rahmawati, S.T., M.T.

$2^{\text {nd }}$ Drs. Sutrisno M.Pd 


\section{PENDAHULUAN}

Pendidikan

mempunyai

peranan yang sangat penting dalam perkembangan dan kelangsungan hidup manusia. Pendidikan menjadi dasar yang harus dimiliki oleh setiap individu agar mampu bertahan dalam persaingan yang semakin ketat diera globalisasi sekarang ini. Perkembangan zaman tidak bisa lepas dari berbagai macam masalah yang muncul tanpa pernah kita pikir sebelumnya. Gambaran masalah yang dihadapi yaitu, rendahnya kualitas peserta didik, pendidik yang kurang professional, serta biaya pendidikan yang terbilang masih mahal.

Setiap individu bebas untuk melanjutkan pendidikan ke jenjang yang lebih tinggi dalam hal ini adalah sekolah menengah. Sekolah tingkat menengah pada dasarnya dibedakan menjadi dua, yaitu sekolah menengah atas dan sekolah menengah kejuruan. Sekolah menengah atas biasanya cenderung mengajarkan pelajaran yang sifatnya ilmu pengetahuan, sedangkan sekolah menengah kejuruan cenderung mengajarkan pelajaran yang sifatnya keahlian. sekolah menengah kejuruan dibagi menjadi beberapa jurusan diantaranya: jurusan bangunan, mesin, elektro dan lain-lain.

Menggambar interior dan eksterior bangunan adalah salah satu mata pelajaran dari jurusan bangunan. Mata pelajaran ini mengajarkan untuk mendesain hunian yang sesuai dengan rancangan atau konsep yang diinginkan.

Berdasarkan observasi yang dilakukan peneliti di SMK Negeri 2
Sukoharjo khususnya pada mata pelajaran menggambar interior dan eksterior bangunan yang diajarkan di kelas XI Teknik Gambar Bangunan, mempunyai nilai rata-rata 74,64 dari standar ketuntasan yaitu sebesar 76 . Siswa yang dinyatakan lulus sebanyak 19 dari 32 siswa dengan persentase yaitu 59\%. Data tersebut menunjukan prestasi belajar siswa masih rendah. Terdapat berbagai masalah yang muncul dalam proses pembelajaran, diantaranya mata pelajaran menggambar interior dan eksterior bangunan membutuhkan waktu yang panjang tetapi pada kenyataannya sangat terbatas sehingga penyampaian materi terkadang tidak selesai. Dari hasil observasi visual motivasi belajar siswa masih kurang, ditandai dengan perhatian siswa pada saat mengikuti pembelajaran. Motivasi belajar mempunyai peranan penting dalam memberikan rangsangan, semangat dan rasa senang dalam proses pembelajaran.

Berdasarkan keadaan tersebut, memerperlukan model pembelajaran kooperatif sebagai solusi untuk mengatasi waktu pembelajaran terbatas. Pembelajaran kooperatif merupakan upaya mengelompokan siswa di dalam kelas ke dalam suatu kelompok kecil agar siswa dapat bekerja sama dengan kemampuan maksimal yang mereka memiliki dan mempelajari satu sama lain dalam kelompok tersebut menurut Jhonson dalam Isjoni (2007: 17).

Model pembelajaran kooperatif yang dipilih adalah metode demonstrasi. Metode demonstrasi dipilih sebagai salah satu cara untuk menciptakan suasana 
pembelajaran yang menarik dan menyenangkan. Metode demonstrasi adalah cara yang digunakan dalam penyajian pelajaran dengan cara memperagakan bagaimana membuat, mempergunakan serta pempraktekan suatu benda atau alat baik asli maupun tiruan atau bagaimana mengerjakan suatu perbuatan atau tindakan yang mana dalam memperagakan disertai dengan penjelasan lisan (Darwyn Syah, 2007: 152).

Selain itu pembelajaran juga menggunakan metode example non example. Contoh (examples) dan noncontoh (nonexamples) adalah benda atau kegiatan yang ada di sekitar peserta didik sebagai wujud materi pembelajaran yang sedang diuraikan baik bersifat positif maupun negatif. Maka guru perlu memberi contoh dan noncontoh yang praktis dan konkret dari uraian konsep yang masih abstrak agar peserta didik jelas menurut pendapat Warsita (2008: 277).

Motivasi adalah tenaga pendorong atau penarik yang menyebabkan adanya tingkah laku ke arah suatu tujuan tertentu. Peserta didik akan bersungguh-sungguh karena memiliki motivasi yang tinggi. Seorang siswa akan belajar bila ada faktor pendorongnya yang disebut motivasi dijelaskan oleh Mulyasa (2003: 112).

Menurut Muhibbin Syah (2008: 91) prestasi belajar adalah taraf keberhasilan murid dalam mempelajari materi pelajaran di sekolah yang dinyatakan dalam bentuk skor yang diperoleh dari hasil tes mengenai sejumlah materi pelajaran tertentu.
Hasil penelitian yang relevan dengan penelitian ini adalah penelitian yang dilaksanakan oleh Riska Aprilia Wardani (2011) dalam penelitian yang berjudul "Pengaruh Metode Demonstrasi Terhadap Prestasi Belajar Mata Kuliah Askeb Ii Persalinan (Standart Asuhan Persalinan Normal) Ditinjau Dari Motivasi Belajar Pada Mahasiswa Prodi Kebidanan Stikes Dian Husada Mojokerto" Dengan hasil penelitian ini adalah terdapat perbedaan prestasi belajar antara kelompok mahasiswa yang diberi perkuliahan menggunakan metode demonstrasi dan metode konvensional, tidak terdapat perbedaan prestasi belajar mahasiswa antara kelompok mahasiswa yang memiliki motivasi tinggi dan motivasi rendah dan tidak terdapat interaksi pengaruh yang signifikan antara penggunaan metode pembelajaran dan motivasi belajar terhadap prestasi belajar askeb II persalinan. Resty Dwi Nanda Safitri (2014) dalam penelitian yang berjudul "Pengaruh Model Cooperative Learning Tipe Example Non Example Terhadap Motivasi Dan Hasil Belajar Biologi Siswa Di Man Yogyakarta II" Dari hasil uji disimpulkan bahwa pembelajaran cooperative learning tipe example non example berpengaruh terhadap motivasi belajar biologi siswa tetapi tidak berpengaruh terhadap hasil belajar biologi siswa.

Berdasarkan latar belakang dan kajian teori yang telah dipaparkan sebelumnya, maka tujuan dari penelitian ini adalah sebagai berikut: (1) Mengetahui perbandingan motivasi belajar menggunakan metode demonstrasi dan metode example non example 
pada mata pelajaran menggambar interior dan eksterior bangunan di kelas XI TGB SMK N 2 Sukoharjo. (2) Mengetahui perbandingan prestasi belajar siswa menggunakan metode demonstrasi dan metode example non example pada mata pelajaran menggambar interior dan eksterior bangunan di kelas XI TGB SMK N 2 Sukoharjo.

\section{METODE PENELITIAN}

Penelitian dan pengujian dilaksanakan di SMK N 2 Sukoharjo Jurusan Teknik Bangunan Kelas XI yang beralamat di Jl. Solo-Wonogiri, Begajah, Sukohajo, Jawa Tengah 57515 Telp. (0271) 591588. Metode yang digunakan dalam penelitian adalah metode eksperimen dengan desain penelitian Intact-Group Comparison. Sampel penelitian diambil sebanyak 32 siswa yang terbagi dalam dua kelas yaitu satu kelas dengan metode demonstrasi dan satu kelas dengan metode example non example. Teknik pengumpulan data yang digunakan dalam penelitian ini adalah dokumentasi, angket dan observasi. Validitas intrumen penelitian dengan menggunakan uji validitas dan reliabilitas. Uji prasyarat analisis terdiri dari uji normalitas dan dan uji homogenitas. Teknik analisis data menggunakan uji beda (t-test).

\section{HASIL DAN PEMBAHASAN}

Hasil perhitungan data skor rata-rata motivasi belajar dengan metode demonstrasi diperoleh nilai tertinggi (maximum) 65 dan terendah (minimum) 52, jumlah nilai keseluruhan (sum) yaitu 1146 dengan rata-rata (mean) sebesar 57,30.

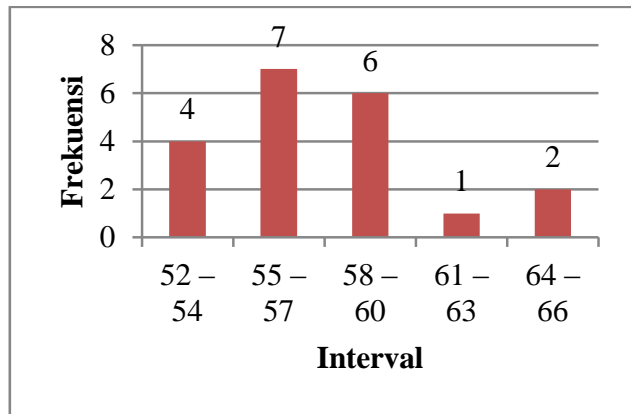

Gambar 1. Histogram Frekuensi Skor Motivasi Belajar Menggunakan Metode Demonstrasi

Hasil perhitungan data skor rata-rata prestasi belajar siswa ranah psikomotorik dan kognitif dengan metode demonstrasi diperoleh nilai tertinggi (maximum) 90 dan terendah (minimum) 80, jumlah nilai keseluruhan (sum) yaitu 1380 dengan rata-rata (mean) sebesar 86,25.

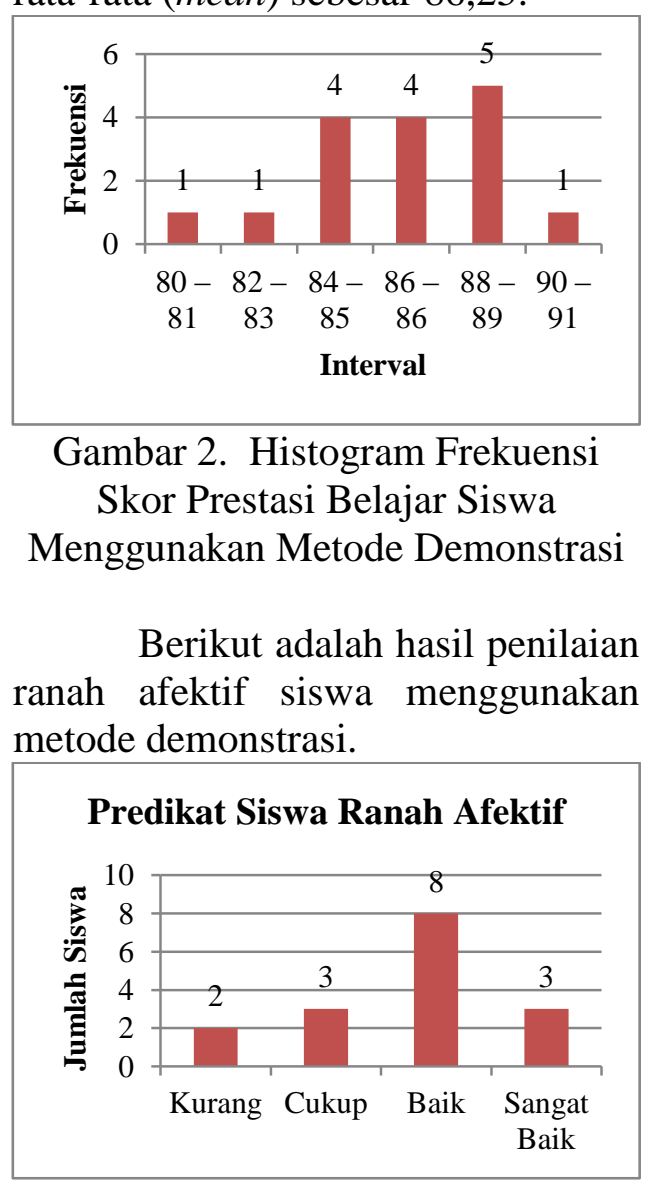


Gambar 3. Histogram Predikat Siswa Ranah Afektif Menggunakan Metode Demonstrasi

Hasil perhitungan data skor rata-rata motivasi belajar dengan metode example non example diperoleh nilai tertinggi (maximum) 59 dan terendah (minimum) 47, jumlah nilai keseluruhan (sum) yaitu 1074 dengan rata-rata (mean) sebesar 53,70 .

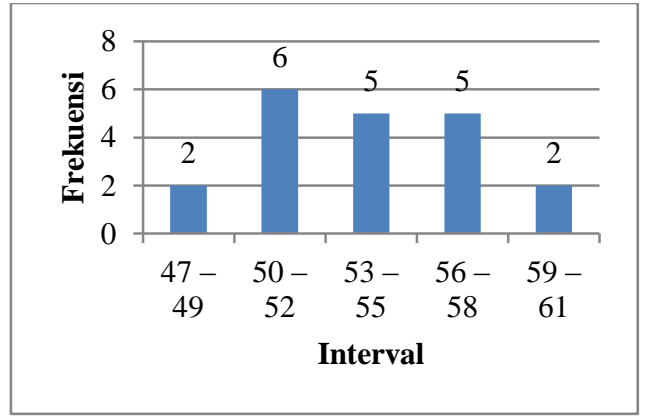

Gambar 4. Histogram Frekuensi Skor Motivasi Belajar Menggunakan Metode Example non Example

Hasil perhitungan data skor rata-rata prestasi belajar siswa ranah psikomotorik dan kognitif dengan metode example non example diperoleh nilai tertinggi (maximum) yang diperoleh 85 dan terendah (minimum) 78, jumlah nilai keseluruhan (sum) yaitu 1308 dengan rata-rata (mean) sebesar 81,75.

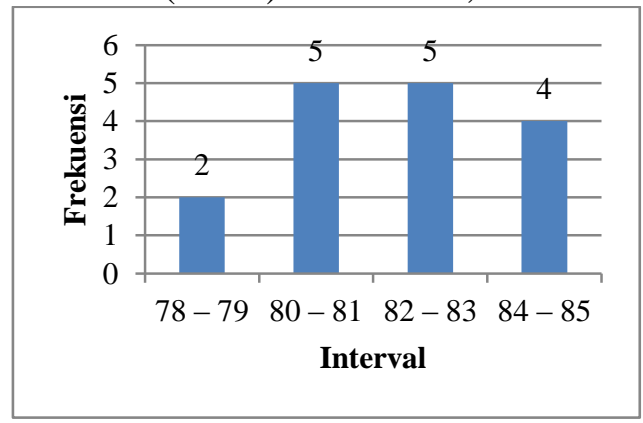

Gambar 5. Histogram Frekuensi Skor Prestasi Belajar Siswa Menggunakan Metode Example non Example
Berikut adalah hasil penilaian ranah afektif siswa menggunakan metode example non example.

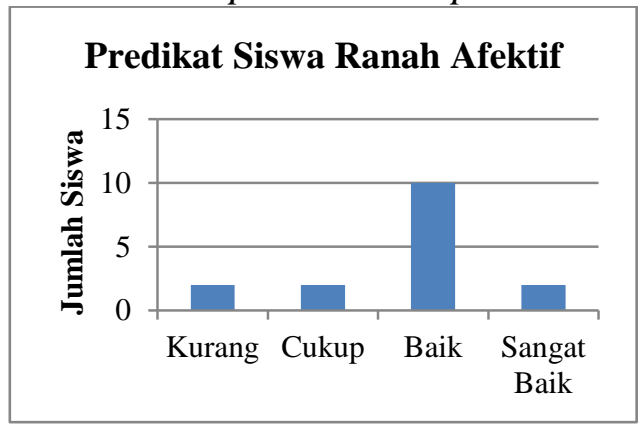

Gambar 6. Histogram Predikat Siswa Ranah Afektif Menggunakan Metode example non example

\section{Perbandingan Motivasi Belajar}

Pada hasil perhitungan pembelajaran menggunakan metode demonstrasi diperoleh skor rata-rata motivasi belajar yang sebesar 57,30, sedangkan pembelajaran menggunakan metode example non example sebesar 53,70. Berdasarkan pengujian menggunakan t-test didapatkan $t_{\text {hitung }} 4,14>t_{\text {tabel }} 2,101$ jatuh pada penerimaan $\mathrm{Ha}$ atau penolakan Ho, sehingga dapat disimpulkan bahwa pembelajaran menggunakan metode demonstrasi memiliki motivasi belajar yang lebih tinggi dibanding pembelajaran menggunakan metode example non example.

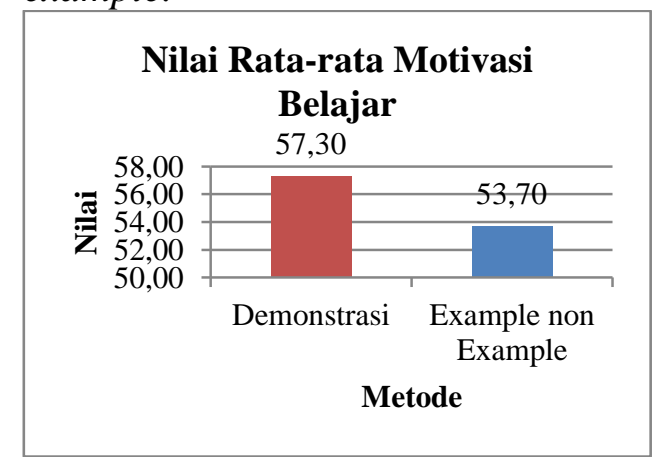

Gambar 7. Perbandingan Nilai RataRata Motivasi Belajar 


\section{Perbandingan \\ Prestasi Belajar}

Pada hasil perhitungan prestasi belajar ranah psikomotorik dan afektif pembelajaran menggunakan metode demonstrasi diperoleh skor rata-rata prestasi belajar yang sebesar 86,25, sedangkan pembelajaran menggunakan metode example non example sebesar 81,75. Berdasarkan pengujian menggunakan t-test didapatkan $t_{\text {hitung }} 7,89>t_{\text {tabel }} 2,145$ jatuh pada penerimaan $\mathrm{Ha}$ atau penolakan Ho, sehingga dapat disimpulkan bahwa pembelajaran menggunakan metode demonstrasi memiliki prestasi belajar yang lebih tinggi dibanding pembelajaran menggunakan metode example non example.

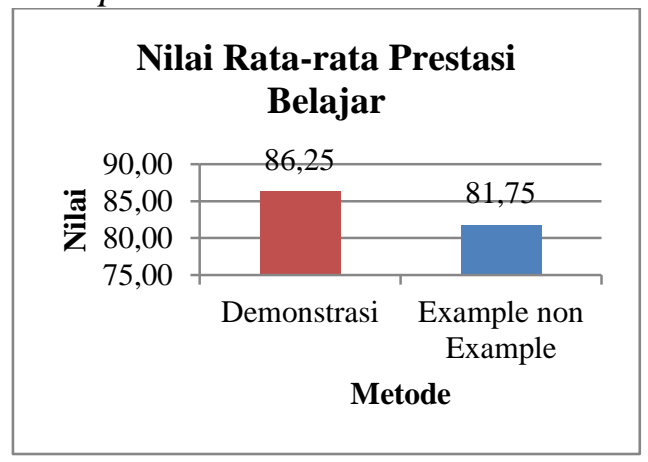

Gambar 8. Perbandingan Nilai Rata-

$$
\text { Rata Prestasi Belajar }
$$

Peningkatan motivasi belajar dipengaruhi oleh perasaan yang timbul dari dalam diri masingmasing siswa yaitu: perhatian, percaya diri dan kepuasan/senang. Dengan metode demonstrasi siswa diajak untuk melakukan percobaan selayaknya ilmuwan, kegiatan tersebut mendorong siswa menumbuhkan rasa ingin tau sehingga timbul motivasi memecahkan masalah yang ada. Dengan membagi dalam beberapa kelompok guru berusaha untuk mengadakan persaingan diantara kelompok lain, dengan demikian motivasi untuk menyelesaikan pekerjaan lebih tinggi. Pada akhirnya berpengaruh baik pada peningkatan pemahaman atau penguasaan materi dan kemampuan berfikir siswa. Prestasi belajar menggunakan metode demonstrasi lebih tinggi dibandingkan dengan metode example non example karena penerapan metode demonstrasi dengan bantuan alat peraga menciptakan suasana pembelajaran yang menyenangkan. Hal ini sependapat dengan Rizka Aprilia Wardani (2011: 70) berpendapat "Penggunakan metode pembelajaran yang menarik maka siswa akan belajar dengan perasaan senang dan penuh antusias sehingga siswa akan lebih mudah menerima dan memahami materi pelajaran yang diberikan sehingga akan meningkatkan prestasi belajar siswa." Berbeda dengan pembelajaran yang berpusat pada guru, informasi yang didapat siswa bukan berasal dari hasil penemuan dari proses yang dilakukan siswa. Akibatnya pengetahuan yang diperoleh siswa hanya sebatas mengetahui bukan memahami. Informasi yang diperoleh dengan cara seperti ini akan lebih cepat terlupakan. Jadi dengan memilih metode pembelajaran yang tepat maka dapat membantu meningkatkan prestasi belajar siswa.

\section{SIMPULAN}

Berdasarkan hasil penelitian yang telah dilakukan, maka dapat diperoleh kesimpulan sebagai berikut: (1) Motivasi belajar yang 
dihasilkan dengan metode demontrasi lebih baik dibandingkan dengan metode example non example pada mata pelajaran menggambar interior dan exterior bangunan di kelas XI TGB SMK N 2 Sukoharjo. (2) Prestasi belajar siswa yang dihasilkan dengan metode demontrasi lebih baik dibandingkan dengan metode example non example pada mata pelajaran menggambar interior dan exterior bangunan di kelas XI TGB SMK N 2 Sukoharjo.

\section{SARAN}

Bagi guru, guru hendaknya menggunakan model pembelajaran dan metode untuk kegiatan pembelajaran di sekolah. Dalam penerapannya perlu memilih metode yang sesuai dengan materi yang akan diajarkan. Dari hasil penelitian ini diharapkan guru menerapkan metode demonstrasi sehingga mampu meningkatkan motivasi belajar dan prestasi belajar siswa.

Bagi siswa, Siswa yang kurang memahami materi dalam mengikuti proses pembelajaran yang sedang berlangsung diharapkan siswa berani bertanya maupun berpendapat mengenai materi yang kurang dipahami.

Bagi peneliti selanjutnya, Untuk peneliti yang ingin mengaji maupun meneruskan penelitian ini perlu memperhatikan beberapa faktor seperti keadaan kelas, ruang kelas, keadaan siswa, dan fasilitas sekolah agar penelitian dapat berjalan lancar dan memberikan hasil sesuai dengan yang diharapkan.

\section{DAFTAR PUSTAKA}

Isjoni. (2007). Cooperative learning Efektivitas Pembelajaran
Kelompok. Bandung:

Alfabeta.

Mulyasa, E. (2003). Kurikulum

Berbasis Kompetensi.

Bandung: Remaja

Rosdakarya.

Safitri, Resty DN. (2014). Pengaruh

Model Cooperative

Learning Tipe Example Non

Example Terhadap Motivasi

Dan Hasil Belajar Biologi

Siswa Di Man Yogyakarta Ii

Syah, Darwyn, dkk (2007).

Perencanaan Sistem

Pendidikan Agama Islam.

Jakarta: Gaung Persada

Perss.

Syah, Muhibbin. (2002). Psikologi

Pendidikan Dalam

Pendekatan Baru. Bandung:

PT. Remaja Rosdakarya.

Wardani, Rizka A. (2011). Pengaruh

Metode Demonstrasi

Terhadap Prestasi Belajar

Mata Kuliah Askeb Ii

Persalinan (Standart Asuhan

Persalinan Normal) Ditinjau

Dari Motivasi Belajar Pada

Mahasiswa Prodi

Kebidanan Stikes Dian

Husada Mojokerto

Warsita. B. (2008). Teknologi

Pembelajaran Landasan

dan Aplikasinya. Jakarta:

Rineka Cipta 